\title{
A INCORPORAÇÃO DE ACORDOS INTERNACIONAIS E DO DIREITO CONSUETUDINÁRIO PELA LEGISLAÇÃO DOMÉSTICA EM UM AMBIENTE LEGAL PLURALISTA. CONSIDERANDO A LEGISLAÇÃO DAS ILHAS DO PACÍFICO EM SAÚDE PÚBLICA COMO ESTUDO DE CASO
}

\author{
INCORPORATING INTERNATIONAL TREATY OBLIGATIONS \\ AND CUSTOMARY LAW INTO DOMESTIC LEGISLATION IN A \\ PLURALIST LEGAL ENVIRONMENT. CONSIDERING \\ PACIFIC PUBLIC HEALTH LAWS
}

AS A CASE STUDY

Genevieve Howse (*) $^{(*)}$

\section{RESUMO}

A maioria dos países integrantes do Fórum das llhas do Pacífico(1) foi colônia ou protetorado britânico. Essa condição resultou na transposição de leis britânicas relativas à saúde pública que necessitam de revisão e reforma. Estes países também contam com uma rica tradição de direito consuetudinário e métodos de organização social anteriores à experiência colonial(2). Acrescente-se a esse ambiente legal pluralista, o fato de que todos os países do Pacífico ratificaram tratados de direitos humanos internacionais ou tratados que criam obrigações no direito internacional em relação à saúde.

(*) Advogada, pesquisadora da Escola de Saúde Pública da Trobe University, Austrália. E-mail: g.houwse@latrobe.edu.au Recebido em 02.12.10. Aprovado em 20.12.10.

(1) ILHAS Cook, Estados Federados da Micronésia, Fiji, Kiribati, Nauru, Niuê, Papua Nova-Guiné, República das Ilhas Marshall, Samoa, Ilhas Salomão, Tonga, Tuvalu, Vanuatu. Disponível em: <http://www.forumsec.org.fj/pages.cfm/about-us/member-countries/>. Acesso em: 15 nov. 2010.

(2) FORSYTH, Miranda. A Bird that Flies with Two Wings - Kastom and State Justice Systems in Vanuatu, ANU E Press, 2009. 


\title{
Palavras-chave
}

Direito Consuetudinário; Direito Sanitário; Ilhas do Pacífico; Princípios dos Direitos Humanos; Saúde Pública.

\begin{abstract}
Most Pacific Island countries which are members of the Pacific Islands Forum have a history as British colonies or protectorates. This delivers a legacy of transplanted British style public health laws from the first half of the twentieth century, which are out of date and in need of review and reform. Pacific Island countries also have a rich tradition of customary laws and methods of social organisation predating their colonial experience. Added to this pluralist legal environment, all Pacific countries have ratified some international human rights treaties or treaties creating obligations at international law in relation to health.
\end{abstract}

\section{Keywords}

Customary Law; Health Law; Human Rights Principles; Pacific Island; Public Health.

Em um projeto de criação de uma lei modelo da saúde pública para a avaliação dos países das llhas do Pacífico, contemplando uma revisão de suas leis de saúde pública, como estas nações podem unir sua rica tradição em direito consuetudinário e incorporar obrigações de direitos humanos, sejam elas provenientes das constituições dos países, de tratados de direitos humanos, ou ainda, do direito consuetudinário internacional? Quais são os pontos que emergem, considerando a incorporação de leis aplicáveis em uma lei modelo de saúde pública, dentro de um ambiente legal pluralista, no qual várias obrigações legais podem ser inconsistentes entre si e incertas em sua aplicação na região única do Pacífico?

\section{INTRODUÇÃO}

Está em processo de finalização, o projeto para a elaboração de uma lei modelo de saúde pública. O projeto será avaliado pelos países que integram o Fórum das Ilhas do Pacífico e concentra-se, em particular, em Vanuatu, Papua Nova-Guiné, Ilhas Salomão e Fiji(3). Esta lei modelo está

(3) HOWSE, G. A Model Public Health Law for the Pacific, Programme Methods. Public Health, v. 123, n. 3, Mar. 2009. 
sendo desenvolvida em módulos, que incluem as questões políticas e as condições para sua implementação, de maneira a colaborar na avaliação que os países farão sobre sua utilidade ${ }^{(4)}$. A lei poderá ser aplicada em sua totalidade ou em partes, de acordo com a conveniência dos Estados, levando-se em consideração a necessidade de revisão ou de emendas em suas leis de saúde pública.

Em um ambiente legal pluralista, como um país gerencia a melhora de seu modelo britânico de direito à saúde pública, ajustando-o ao ambiente único do Pacífico, enquanto cumpre com obrigações de tratados internacionais de direitos humanos, particularmente o direito à saúde, e assegurando a sensibilidade do direito consuetudinário? O resultado deve ser uma lei de fácil compreensão e aplicação, que será uma ferramenta construtiva para auxiliar os governos do Pacífico na implementação políticas de prevenção de doenças e de melhoria da saúde da população.

O pluralismo legal é definido como:

Um [sistema] no qual o direito e as instituições legais não estão inseridos dentro de um "sistema", mas têm suas fontes nas atividades autoregulatórias que podem sustentar, complementar, ignorar ou frustrar uma a outra, sendo que a "lei" realmente eficaz na "base" da sociedade é o seu resultado(5).

Em ambientes de legalidade pluralista, as leis com estilo ocidental e as obrigações legais internacionais são pobremente compreendidas e, algumas vezes, completamente desconhecidas da população rural dos países do Pacífico.

"A lei é, muitas vezes, um conceito novo ou estrangeiro. Quando você fala coisas na lei como se fossem feitas na comunidade, eles entendem como algo que estrangeiros imaginaram e querem que nós sigamos e tudo o mais (EHO4)."(6)

Em um estudo de caso na vila de Mangaliliu, próxima de Port Vila, capital de Vanuatu, um pesquisador notou que: "A maioria das pessoas não tem uma ideia clara do que é saúde pública e ninguém sabe que há leis relacionadas com a saúde pública". ${ }^{(7)}$

Este artigo engloba uma série de trabalhos sobre a criação de uma lei modelo de saúde pública para o Pacífico ${ }^{(8)}$. Consideramos aqui um conjunto

\footnotetext{
(4) Id. Ibid.

(5) FORSYTH, Miranda. op. cit.

(6) Aspas de um oficial da saúde em entrevista conduzida dentro do projeto de lei modelo de saúde pública do Pacífico.

(7) JOWITT, Foukona; Tom'Tavala. Model Public Health Law for the Pacific Project-Customary Law and Public Health, Unpublished Paper by Scholars from the University of the South Pacific for the Model Public Health Law for the Pacific Project. At the time of writing, there were plans to submit the paper for publication along with a series of papers on the project. Journal of South Pacific Law, p. 21, 2011.

(8) 1. Artigo sobre a racionalidade e metodologia para um projeto de pesquisa, já publicado. (HOWSE, G. op. cit.); 2. Artigo sobre as obrigações constitucionais e de tratados referentes aos
} 
confuso de leis e obrigações legais, sejam locais, "caseiras" ou "transplantadas", que devem ser avaliadas pelos países das Ilhas do Pacífico na revisão ou emenda de suas leis de saúde pública. Também identificamos as dificuldades em se trabalhar com um conjunto desconcertante de obrigações legais independentes e, às vezes, incoerentes. Buscamos abordar estas questões de forma a construir uma legislação útil, prática e acessível, que possa contribuir para os governos na promoção da saúde e prevenção de doenças. Ao fim, elencamos oportunidades para a inclusão da proteção dos direitos humanos de forma compatível com as obrigações constitucionais, os tratados ratificados e as leis e costumes locais.

Para a tarefa de identificação de oportunidades no uso das leis costumeiras, utilizamos trabalhos de pesquisadores da Universidade do Sul do Pacífico, os quais compõem uma série de artigos desenvolvidos no âmbito do projeto de desenvolvimento da lei modelo da saúde pública para o Pacífico ${ }^{(9)}$. A possibilidade de aplicação de obrigações acordadas em tratados e de abordagens baseadas nas leis locais pode ter uma função mais ampla de revisão e mudança da legislação em saúde em muitas regiões.

\section{ACORDOS DE DIREITOS HUMANOS}

Como resultado da Segunda Grande Guerra Mundial, a revelação dos horrores da guerra e do tratamento dado aos civis, pelos seus próprios governos, chocaram a comunidade internacional e chamaram os povos à ação. Em um esforço de cooperação para evitar que tais atrocidades acontecessem novamente, a comunidade internacional codificou os direitos humanos fundamentais de tal maneira que pudessem ser aceitos por todos como universais. Este esforço culminou, em 1948, com a adoção

\footnotetext{
direitos humanos e a lei de saúde pública para os 14 países das Ilhas do Pacífico; 3. Artigo analisando e comparando elementos da legislação em saúde atual do Pacífico; 4. Artigo sobre como as leis de saúde pública são usadas pelos trabalhadores da saúde; 5 . Artigo sobre os possíveis usos do direito consuetudinário em uma lei modelo de saúde pública para o Pacífico; 6 . Artigo sobre o que deve ser incluído em uma série de opções legislativas, considerando os países do Pacífico. Trata-se de uma série de "módulos" legislativos dos quais as nações podem escolher aqueles aos quais elas se adequam melhor; 7. Artigo sobre as complexidades em se incorporar obrigações de tratados internacionais, leis de saúde pública "ocidentalizadas" e o direito consuetudinário local em uma lei modelo mais adequada ao ambiente do Pacífico; 8. Artigo sobre as oportunidades de abordagens regionais da lei de saúde pública e 9 . Guia para a revisão da legislação de saúde pública do Pacífico, incorporando a lei modelo de maneira modular. Os primeiros oito artigos estão sendo preparados para publicação e serão submetidos ao Journal of South Pacific Law, edição de Dezembro de 2011, com exceção do artigo de número 7 (este trabalho). O artigo de número 9 será uma publicação separada, destinada aos servidores do Ministério da Saúde.

(9) JOWITT, Foukona; Tom'Taval. op. cit. artigo inédito dos pesquisadores da Universidade do Sul do Pacífico.
} 
pela Assembleia Geral das Organizações das Nações Unidas (ONU), da Declaração Universal dos Direitos Humanos. Estes direitos foram posteriormente articulados em convenções. Em 1966, o Pacto Internacional dos Direitos Civis e Políticos e o Pacto Internacional dos Direitos Econômicos, Sociais e Culturais foram adotados pela ONU.

Quais são as obrigações legais para implementar a Declaração Universal dos Direitos Humanos e o Pacto Internacional dos Direitos Econômicos, Sociais e Culturais e como estas obrigações afetam o desenvolvimento de uma lei modelo de saúde pública do Pacífico?

\section{Declaração Universal dos Direitos Humanos}

Em seu preâmbulo, a Declaração Universal dos Direitos Humanos afirma-se como padrão a ser alcançado por todos os povos e nações. De acordo com o documento, cada indivíduo e instituição da sociedade deve, por meio da educação, promover o respeito aos direitos e liberdades declarados no texto. As transformações devem acontecer progressivamente, para assegurar o reconhecimento universal e efetivo e a observância dos direitos $^{(10)}$.

Originariamente o documento foi concebido como uma declaração de objetivos a serem buscados pelos governos. Não é um tratado e, portanto, não está vinculado ao direito internacional. A ONU o descreve como: [um documento] com força moral, representando o primeiro acordo internacional que define os direitos dos povos, adotado após um período de massivas violações contra os direitos que ele descreve."(11)

É um mecanismo poderoso para ser usado como pressão diplomática junto aos Estados que violam os princípios da Declaração. Argumenta-se que, como os Estados têm, nos últimos 50 anos, constantemente recorrido ao documento, ele tornou-se parte do direito consuetudionário internacional.

(10)V. United Nations, UNDHR, Questions and Answers. Disponível em: <http://www.udhr.org/history/ question.htm\#_Toc397930429>. Acesso em: 18 out. 2010. Embora o registro mostre que a maioria dos países que adotaram a Declaração não o vissem como um documento juridicamente vinculativo, o impacto jurídico da Declaração tem sido muito maior do que talvez seus autores tenham imaginado. Hoje, a referência direta à Declaração é feita nas constituições de muitos países que se tornaram independentes depois da divulgação do documento. Primeiros-ministros, presidentes, deputados, juízes, advogados, juristas, ativistas de direitos humanos e pessoas comuns em todo o mundo aceitaram a Declaração como um código legal essencial. Dezenas de tratados internacionais juridicamente vinculativos são baseadas nos princípios estabelecidos na Declaração e o documento foi citado como justificativa para várias ações das Nações Unidas, incluindo os atos do Conselho de Segurança.

(11) OFFICE of the UN High Commissioner for Human Rights, An introduction to the core human rights treaties and the treaty bodies, Fact Sheet No 30. Disponível em: <http://www.ohchr.org/ Documents/Publications/FactSheet30en.pdf>. Acesso em: 27 out. 2010. 
Entretanto, o Pacífico é o exemplo de uma região onde a inovocação do texto pode ter efeito duvidoso. Há muitos países nos quais a existência do Estado de Direito, ou sua aceitação consistente, é incerta. A adesão doméstica aos termos da Declaração é menos provável:

nas circunstâncias atuais que podemos chamar de "globalismo emergente", é prematuro presumir que noções como "constitucionalismo" e "respeito ao Estado de Direito" estão difundidas em todos as sociedades ou mesmo nos sistemas legais - ou que estas noções, estando difundidas, tenham um significado singular, finalidade ou destaque. ${ }^{(12)}$

Enquanto pesquisadores do direito discutem a transição da Declaração Universal para o direito consuetudinário ${ }^{(13)}$, muitas constituições do Pacífico adotaram, especificamente, alguns dos direitos afirmados, criando uma clara obrigação legal. As constituições de Kiribati, de Nauru, das Ilhas Salomão e de Tuvalu contêm resoluções sobre direitos e liberdades fundamentais influenciadas pelo documento.

Nas Ilhas Salomão, está em elaboração uma carta constitucional, para substituir a constituição atual, garantindo 12 direitos ${ }^{(14)}$, com base em direitos europeus, como expressados na Declaração Universal. Um comentarista do Pacífico destaca que:

estes direitos foram transplantados do Ocidente e refletem valores que são fundamentalmente diferentes daqueles subjacentes ao sistema de direito tradicional. Por exemplo, os direitos humanos enfatizam os direitos individuais, a liberdade e a igualdade; enquanto o direito consuetudinário destaca os valores comunitários, posição e deveres. ${ }^{(15)}$

Sugere-se adiante que garantias em acordos de direitos humanos refletem preocupações de países ocidentais. As prioridades dos países em desenvolvimento podem ser diferentes quando, por exemplo, o índice de mortalidade infantil é alto e os índices de alfabetização e de Produto Interno Bruto, baixos ${ }^{(16)}$. Um pesquisador local afirma que há poucas evidências de que o capítulo sobre direitos da carta constitucional das Ilhas Salomão tenha sido negociado a partir de uma agenda doméstica ou que tenha se atentado para circusntâncias particulares do país ${ }^{(17)}$.

(12) HASSALL, G. Constancy and Change; A Perspective on Constitutional Reform "the Pacific Way", Conference Paper at Fourteenth Annual Public Law Weekend, Centre for International and Public Law, Australian National University, Canberra, 12-13 November 2009. p. 2.

(13) TRINDADE, Antônio Augusto Cançado. Introduction to the Universal Declaration of Human Rights. Disponível em: <http://untreaty.un.org/cod/avl/ha/udhr/udhr.html>. Acesso em: 17 nov. 2010.

(14) Incluem os direitos à vida, liberdade, segurança, proteção da lei e privacidade, liberdade de consciência, expressão, reunião e associação, v. CORRIN, Jennifer. Breaking the Mould: Constitutional Review in the Solomon Islands. Revue Juridique Polynesienne, n. 13, 2007.

(15) CORRIN, Jennifer. op. cit., p. 147.

(16) Id., loc. cit.

(17) Id. Ibid., p. 157. 
A constituição de Papua Nova-Guiné contempla tanto os direitos fundamentais como os direitos qualificados. Os direitos fundamentais incluem o direito à vida, à prevenção de tratamento desumano e à proteção da lei ${ }^{(18)}$. Direitos qualificados incluem a liberdade individual; prevenção contra trabalho escravo e arbitrariedade; liberdade de consciência, de expressão e religiosa; liberdade de reunião; direito ao voto, entre outros ${ }^{(19)}$. As restrições aos direitos qualificados podem ser tomadas com base no interesse público, especialmente em áreas como a saúde pública. Estes direitos têm se provado difíceis de se interpretar, compreender e aplicar(20)(21)(22)(23).

\section{O Pacto Internacional dos Direitos Econômicos, Sociais e Culturais}

É o documento que articula especificamente o direito aos mais altos padrões de saúde física e mental(24); trata-se de um importante tratado para o desenvolvimento de uma lei da saúde pública. O Pacto ${ }^{(25)}$ é legalmente vinculante, diferente da Declaração Universal dos Direitos Humanos e tem como princípio uma implementação progressiva: "Compromete-se a tomar medidas... até o máximo de seus recursos disponíveis, com vista a alcançar progressivamente a plena realização dos direitos reconhecidos [no Pacto]".(26)

O princípio da realização progressiva reconhece as dificuldades que os Estados-Membros podem ter devido à limitação de recursos. Entretanto, o documento também impõe a obrigação imediata de se tomar medidas concretas e direcionadas à plena realização dos direitos afirmados.

(18) Constitution of the Independent State of Papuan New Guinea, Sections 35, 36 and 37.

(19) Constitution of the Independent State of Papuan New Guinea, Sections 42 to 56.

(20) FORSYTH, Miranda. p. cit.

(21) CORRIN, Jennifer. op. cit.

(22) HASSALL, G. op. cit.

(23) JOWITT, Anita. The Future of Law in the South Pacific. Journal of South Pacific Law, v. 12, n. 1, 2008. Disponível em: <http://www.paclii.org/journals/fJSPL/vol12no1/pdf/jowitt.pdf>. Acesso em: 19 nov. 2010.

(24) O trabalho lista alguns passos a serem tomados pelos Estados como: a redução no número de natimortos e da mortalidade infantil; desenvolvimento saudável da criança; melhoria da higiene industrial e ambiental; prevenção, tratamento e controle de doenças e acesso a cuidados médicos. $\mathrm{V}$. WHO. Health and human rights, the international covenant on economic, social and cultural rights. Disponível em: <http://www.who.int/hhr/Economic_social_cultural.pdf>. Acesso em: 02 nov. 2010. (25) Um pacto é um acordo juridicamente vinculante, validado com a ratificação de um certo número de países. O artigo 26 da Convenção de Viena sobre o Direito dos Tratados afirma que "Todo tratado em vigor obriga as partes e deve ser cumprido por elas de boa-fé". Uma declaração não é legalmente vinculante, mas tem um peso moral, por ser adotada pela comunidade internacional. V. AUSTRALIAN HUMAN RIGTS COMMISSION. Disponível em: <http://www.hreoc.gov.au/education/hr_explained/ 5_international.html>. Acesso em: 27 out. 2010.

(26) Pacto Internacional dos Direitos Econômicos, Sociais e Culturais, Article 2(1). V. IESCR Article 2(1). See See WHO, Health and Human Rights, the International Covenant on Economic, Social and Cultural Rights. Disponível em: <http://www.who.int/hhr/Economic_social_cultural.pdf>. Acesso em: 02 nov. 2010. 
Os Estados-Membros que ratificaram o Pacto têm a obrigação, pelo direito internacional, de tornar o documento efetivo em seus territórios ${ }^{(27)}$. A maneira como isto se dá é responsabilidade de cada nação( ${ }^{(28)}$. Como todos os pactos internacionais, o acordo respeita a soberania nacional e não impõe obrigações legais absolutas. Ele não é "autoaplicável": requer que leis nacionais sejam aprovadas para implementar suas garantias. Os artigos do Pacto não são parte do direito nacional da maioria dos Estados-Membros até que sejam transformados em uma lei constitucional ${ }^{(29)}$ ou uma lei parlamentar. Sem isso, o Pacto não tem efeito direto ${ }^{(30)}$.

Em 2000, o Comitê dos Direitos Econômicos, Sociais e Culturais divulgaram a Nota Explicativa n. 14 com o objetivo de definir a amplitude e a interpretação do art. 12:

De acordo com esta Nota Explicativa, o direito à saúde abrange "uma ampla gama de fatores socioeconômicos para a promoção de condições pelas quais as pessoas possam ter uma vida saudável, inclusive os determinantes básicos de saúde, como alimentação e nutrição, moradia, acesso à água potável e a condições adequadas de saneamento, condições seguras e saudáveis de trabalho e meio ambiente saudável". A Nota Explicativa especifica que a viabilidade, acessibilidade (incluindo a não discriminação, acessibilidade física e acesso à informação), aceitabilidade e qualidade são inerentes ao direito à saúde.

(27) Estas regras resultam de uma longa prática entre os países, que as aceitaram como normas vinculantes em suas relações mútuas. Entretanto, elas são vistas como direito coonsuetudinário internacional. Desde que surgiu um movimento para sua codificação, dois pactos internacionais foram negoaciados. A Convenção de Viena sobre o Direito dos Tratados, de 1969, em vigor desde 27 de janeiro de 1980, contém regras para tratados acordados entre os países. Para ser considerado um "tratado", de uma maneira geral, um instrumento tem que ir ao encontro de certos critérios. O primeiro deles é de que deve ser um instrumento juridicamente vinculante, o que significa que as partes têm direitos legais e deveres. Em segundo lugar, o texto deve ser elaborado por Estados ou organizações internacionais com poderes elaboradores. Em terceiro, deve ser regido pelo direito internacional. Finalmente, o engajamento deve ser escrito. O termo genérico "pacto" é sinônimo do termo genérico "tratado". A ratificação define o ato internacional por meio do qual o Estado indica seu consentimento de se vincular a um tratado. A instituição da ratificação garante aos Estados o tempo necessário para aprovar o documento em nível doméstico e para providenciar a legislação nacional necessária para torná-lo efetivo. [Arts.2 (1) (b), 14 (1) and 16, Vienna Convention on the Law of Treaties 1969]. UN, United Nations Treaty Reference Guide. Disponível em: <http:// untreaty.un.org/English/guide.asp>. Acesso em: 18 nov. 2008.

(28) O Pacto utiliza termos em relação às obrigações dos Estados-Membros como "ao máximo de seus recursos disponíveis". Obviamente, a decisão sobre quais medidas são apropriadas e quais recursos estão disponíveis pertencem aos Estados-Membros.

(29) Um exemplo é a Section 117 Constitution of the Independent State of Papua New Guinea

(30) Entretanto, isso pode ser usado para interpretar leis dos Estados-Membros, dentro de uma comunidade de nações, quando há dúvidas sobre o significado. Há precedentes nas cortes de outras comunidades de nações que utilizam as convenções da ONU para interpretar as leis domésticas em tais situações. V. KIRBY, J. The First Ten Years of the Bangalore Principles on the Domestic Application of International Laws. Disponível em: <http://www.hcourt.gov.au/speeches/kirbyj/ kirbyj_bang11.htm>. Acesso em: 04 fev. 2009. 
Além do dever com seus cidadãos, os Estados-Membros do Pacto têm a obrigação internacional de respeitar o direito à saúde dos cidadãos de outros países. ${ }^{(31)}$

Na região do Pacífico, é fato que, entre os 14 países que integram o Fórum do Pacífico Sul, somente dois são signatários do Pacto (Ilhas Salomão, em 1982, e Papua Nova-Guiné, em 2008). Portanto, a maioria dos países do Pacífico não tem obrigações internacionais vinculadas a este documento, no que diz respeito ao direito à saúde. Para estas nações, não há deveres legais de adotar este direito além do que determinado em suas constituições ou leis de saúde pública, embora não haja nenhum impedimento para a adoção dos princípios do Pacto se os países assim decidirem.

Já as Ilhas Salomão e Papua Nova-Guiné têm a obrigação de implementar, gradualmente, os mais altos padrões de saúde física e mental. São países que devem levar em consideração a Nota Explicativa n. 14, na interpretação do direito à saúde, embora, ela não se constitua em uma obrigação jurídica ${ }^{(32)}$.

\section{INCORPORANDO TRATADOS NAS LEIS NACIONAIS DOS PAÍSES DO PACÍFICO}

Na região do Pacífico, existem significativas obrigações legais incluídas em algumas constituições relativamente recentes, possíveis obrigações decorrentes do direito consuetudinário internacional e obrigações para as Ilhas Salomão e Papua Nova-Guiné, pela ratificação do Pacto Internacional dos Direitos Econômicos, Sociais e Culturais. Como os países devem abordar estes deveres para implementar tratados nacionalmente?

A implementação de obrigações de direitos humanos pode provar-se difícil em países em desenvolvimento, com tradição legal pluralista, onde os conceitos sobre direitos humanos são novos e não necessariamente consistentes com as abordagens tradicionais da organização social.

Um pesquisador descreveu as tentativas de organizações não governamentais e governamentais de incorporar instituições sociais indígenas, como o sistema de parentesco, com modelos transnacionais, como o de proteção de mulheres e conceitos de direitos humanos, proteção contra a violência, dessa maneira: "O resultado é uma montagem de elementos em relações

(31)COMMITTEE on Economic, Social and Cultural Rights. Global Governance watch. Disponível em: <http://www.globalgovernancewatch.org/resources/general-comment-no-14-the-right-to-the-highestattainable-standard-of-health>. Acesso em: 03 nov. 2010.

(32) Shiyan SUN. The Understanding and Interpretation of the ICCPR in the context of China's Possible Ratification. Chinese Journal of International Law, v. 9, n. 3, p. 17-42, Sept. 2010. 
que se transformam constantemente, feitas de elementos que não necessariamente se harmonizam."(33)

Há limitações, nos pactos internacionais, que obrigam os países a cumprir os tratados, destinados à aplicação uniforme em todos os países do mundo dispostos a ratificá-los formalmente.

Claro que é impossível compreender as complexidades de uma tradição particular quando um comitê está negociando com oito países diferentes em duas semanas. Não se pode esperar que os integrantes do comitê gastem um mês lendo literatura antropológica e duas semanas entrevistando as pessoas nascidas em Fiji para determinar o sentido da tradição. ${ }^{(34)}$

Em outubro de 2008, um editorial publicado pelo National, jornal impresso da Papua Nova-Guiné, sobre a implementação do Comitê para a Eliminação de todas as Formas de Discriminação contra a Mulher, elegantemente resumiu o dilema dessa maneira:

Chegar a uma abordagem aceitável, globalmente vinculante, que frequentemente difere de situações domésticas, traz grandes problemas em termos globais. Como transpor a abordagem global para os direitos das mulheres e trazê-los para diferentes comunidades do contexto local da Papua Nova-Guiné? É apropriado que tentemos fazê-lo ou estamos caminhando cegamente para uma rua sem saída?

As considerações expressadas pelos comentaristas do Pacífico mostram o sentimento de ameaça com relação ao uso indiscriminatório de soluções importadas para resolução de problemas locais. Uma avaliação cuidadosa da "adequação" dos requisitos dos acordos internacionais e a situação da região do Pacífico onde eles serão implementados é vital para o sucesso dos acordos internacionais.

É importante que os advogados da área dos direitos humanos levem em consideração o contexto particular da soberania das nações antes de sugerirem reformas nas leis para a realização de tais direitos. As nuanças culturais e de costumes não são facilmente compreendidas por aqueles que não são familiares com a história, a cultura, as tradições e os métodos de organização social de um país em particular.

Os principais atores da advocacia na área dos direitos humanos em nível nacional são tipicamente as elites educadas de maneira transnacional,

(33) MERRY, Sally Engle Legal Transplants and Cultural translation: Making Human Rights in the Vernacular. In: Human Rights and Gender Violence - Translating International Law into Local Justice, University of Chicago Press, 2006. p. 35.

(34) MERRY, Sally Engle quoted. In: GOODALE; MERRY (Eds), The Practice of Human Rights Tracking Law Between the Global and the Local, Cambridge University Press, 2007. p. 2. 
as quais fazem parte do mesmo mundo transnacional, como aqueles especialistas que representam os governos em encontros da ONU... Mesmo em países com um legado colonial britânico, os direitos humanos têm menos força do que os direitos locais enraizados ${ }^{(.35)}$

Como nação soberana, cada Estado-Membro pode cumprir com as obrigações legais de sua própria maneira, refletindo seu ambiente econômico, social, geográfico, cultural e político. As opiniões também podem variar sobre o que significa "cumprimento". Os artigos dos tratados internacionais são generalistas. Os países têm liberdade para implementar políticas em áreas que ultrapassam os requisitos acordados. Em outros campos, a realização "em etapas" pode ser uma maneira de reconhecimento da necessidade de ação para se caminhar em direção à implementação, mas também uma forma de reconhecimento de que a política e a agenda de reformas de cada país podem tomar tempo considerável para chegar a um nível no qual a plena realização dos tratados seja política, econômica ou culturalmente possível.

Propostas de reformas devem ser praticáveis e sustentávies. Como países são diferentes, as maneiras de cumprir com obrigações legais também diferem.

A mensagem do Comitê Constitucional da Papua Nova-Guiné e de pesquisadores estrangeiros e do Pacífico é consistente. Leis não são efetivas por si mesmas apenas porque foram aprovadas, principalmente leis criadas a partir de documentos transnacionais, estrangeiros à região. Em nações como as das Ilhas do Pacífico, que têm métodos de organização cívica muito antigos e mais em consonância com a população do que os sistemas legais importados do Ocidente, em particular nas áreas rurais, deve-se ter muito cuidado ao introduzir reformas "embaladas para se ajustar" dentro de ideias e histórias que dão contornos à vida na cidade moderna. O sentido de "realização progressiva" pode ser utilmente interpretado para considerar o contexto. Da mesma maneira, é importante notar que o art. 1ํ do Pacto Internacional dos Direitos Econômicos, Sociais e Culturais afirma que: "Todos os povos têm o direito à autodeterminação. Em virtude desse direito, determinam livremente seu estatuto político e asseguram livremente seu desenvolvimento econômico, social e cultural."

Este direito suporta uma abordagem de realização progressiva que é influenciada pela cultura e contexto.

A mistura de conceitos de direitos humanos com significados locais de organização comunitária e direito consuetudinário pode criar um discurso sobre a elaboração de leis e direitos distante de textos que apresentam regras rígidas de aplicação de direitos em todos os países.

(35) MERRY, Sally Engle Legal Transplants and Cultural translation: Making Human Rights in the Vernacular, cit., p. 135. 
a alegada universalidade dos direitos humanos, quando confrontada com a contingência de sua aplicação em contextos instruídos por uma estrutura normativa alternativa, inicia um processo cíclico que reconstrói e desestabiliza a alegada universalidade dos direitos humanos como um discurso monolítico(36)

O Pacífico é uma região na qual o ordenamento legal pluralista ou uma multiplicidade de formas de leis podem ser fundidos em virtualmente cada país da região(37). Como um comentador afirmou: "A existência de sistemas legais normativos operando independentemente, ou semi-independentemente em cada Estado, como o sistema Kastom, em Vanuatu, é uma realidade empírica para quase todos os países descolonizados no mundo."(38)

Em artigo recente publicado pelo jornal Journal of South Pacific Law, um comentarista do Pacífico observou que, para o povo da região que vive longe das capitais, a ideia de uma lei e organização social formais é menos significativa ou relevante.

Nos países da região do Pacífico Sul, o conceito ocidental de lei não é tão difundido. Afeta o dia a dia das pessoas de maneira muito limitada (se tanto). Isto acontece, em parte, porque as instituições estatais têm, usualmente, um escopo mais limitado. Por questões geográficas e de recursos, muitos órgãos do sistema legal estatal estão concentradas nas áreas urbanas e, simplesmente, não estão presentes nas "ilhas exteriores" ou áreas rurais. Além disso, para a maioria das populações dos países integrantes do Pacífico Sul, existe um sistema dual de vida, sendo que o sistema tradicional é o mais familiar e muitas vezes mais efetivo. Mas, mesmo que não houvessem limitações no escopo das leis e instituições estatais, elas simplesmente não seriam particular-mente relevantes para proporcionar ordem e mediar disputas em áreas onde o direito consuetudinário e a autoridade tradicional operam. ${ }^{(39)}$

Em Papua Nova-Guiné, os Objetivos Nacionais e Princípios Diretivos estão delimitados na Constituição. O quinto objetivo é alcançar o desenvolvimento, primariamente por meio da utilização das formas de organização social, política e econômica da população do país. O povo exigiu:

Uma reorientação fundamental de nossas atitudes e das instituições governamentais, do comércio, da educação e religiosas em direção a

(36) WASTELL, Sari, Being Swazi, Being Human: Custom, Constitutionalism and Human Rights in an African Polity. In: GOODALE; MERRY (Eds). The Practice of Human Rights; Tracking Law between the Global and the Local, Cambridge University Press, 2007.

(37) FORSYTH, Miranda. op. cit., p. 36.

(38) Id. Ibid., p. 29.

(39) JOWITT, Anita. op. cit. 
formas de participação, consulta e consenso da população papuásia e uma contínua renovação da receptividade destas instituições para com as necessidades e atitudes do Povo. ${ }^{(40)}$

Enquanto os Objetivos Nacionais e Princípios Diretivos não são sujeitos à autoridade judiciária ${ }^{(41)}$, é um dever de todos os órgãos do governo aplicá-los e efetivá-los de acordo com a competência de cada um ${ }^{(42)}$. Este princípio é definido na Constituição como uma meta para a aplicação do modo de abordagem de organização social da população paupásia. Outras constituições como a de Vanuatu, das Ilhas Salomão e de Fiji protegem as abordagens tradicionais das leis e da organização social. Estas garantias constitucionais criam uma obrigação legal de reconhecimento da soberania das nações e de seu direito de organizarem a sociedade de acordo com suas próprias culturas. Isto se aplica à implementação de deveres acordados em tratados nas leis nacionais.

Como opinou um comentarista do Pacífico:

A lei do Estado é sempre tratada como sendo estrangeira... O questionamento explícito da lei do Estado significa que a ficção da legalidade é constantemente exposta. A ordem legal somente funciona se as pessoas acreditam na lei e conscientemente, ou mais frequentemente, inconscientemente, concordam em obedecê-la. Quando esta crença na lei e o acordo (inconsciente) vinculado a ela falham então a fragilidade da ordem legal é desnudada. A fragilidade da ordem legal e estatal é também desafiada pela imensa rapidez das mudanças nos países-membros do Pacífico e pelo desejo de "desenvolvimento" sem um consenso claro sobre o que é este desenvolvimento. ${ }^{(43)}$

Como um ministro da Saúde pode encontrar um caminhgo dentro da confusão entre tradição legal e obrigação? Como pode criar uma lei que vá ao encontro das obrigações legais internacionais e do seu próprio ambiente legal pluralista, onde o direito consuetudinário é frequentemente o único reconhecido e compreendido pela população que vive em vilas tradicionais, distantes das cidades, e com baixa escolaridade?

Este artigo não sugere que a incorporação dos princípios dos direitos humanos na legislação de saúde pública do Pacífico não seja importante. Porém, argumentamos que deve ser feita uma profunda reflexão sobre a revisão de qualquer legislação para o acréscimo de tratados de direitos

(40) Constitution of the Independent State of Papua New Guinea, National Goals and Directive Principles, 5(1).

(41) Constitution of the Independent State of Papua New Guinea, section 25 (1)

(42) Constitution, section 25 (2)

(43) JOWITT, Anita. op. cit., p. 2. 
humanos, começando pela consideração do contexto dos países e de suas tradições legais e de organização social.

Sem uma reflexão sobre a aplicação e a implementação, incluir princípios de direitos humanos de tratados da ONU dentro de leis domésticas pode constituir-se em mais um transplante alienígena impraticável em uma região que já sofreu vários deles. Leis que não são vistas como familiares e que são incompreensíveis localmente não podem ter sucesso, estejam elas na constituição ou não. A carta constitucional das Ilhas Salomão mostra que a incorporação dos princípios dos direitos humanos em uma lei nacional é difícil e frequentemente levanta dúvidas legais sobre sua interpretação e aplicação(44).

\section{DECLARAÇÃO DE PARIS SOBRE A EFICÁCIA DA AJUDA AO DESENVOLVIMENTO}

Alguns dos objetivos da Declaração impedem doações, forçando uma agenda de reforma dos direitos humanos junto a países receptores relutantes, como mostramos a seguir, com sugestões para se iniciar uma reforma legislativa que inclua obrigações de tratados transnacionais considerando a cultura e o contexto locais. O alinhamento com as prioridades nacionais pode ser considerado parte desta preocupação. Este artigo também propõe sugestões com relação à incorporação da Declaração de Paris em uma lei modelo de saúde pública para o Pacífico.

\section{Direito consuetudinário}

Quando países consideram como sua obrigação incorporar os tratados de direitos humanos nas leis locais, aqueles com tradições legais pluralistas, como as nações das Ilhas do Pacífico, devem levar em conta o papel e a aplicação do direito consuetudinário local. Deve-se ter precaução na discussão de tradições e do direito consuetudinário no Pacífico. Os pesquisadores da Universidade do Pacífico Sul mostraram cautela sobre o assunto:

Reformadores da lei devem ser cautelosos em fazer generalizações sobre tradições em uma região com tamanha diversidade de culturas e de costumes. A região do Pacífico é muito diversa. Dentro dela existem muitas culturas diferentes, cada uma com suas tradições e leis. Sistemas de governança modernos também variam, assim como economias e

(44) CORRIN, Jennifer. op. cit. 
desenvolvimento humano. Este é o desafio de uma reforma legislativa - cada país do Pacífico é singular e uma solução do tipo "tamanho único" não será apropriada. ${ }^{(45)}$

\section{O que as constituições dos países do Pacífico dizem sobre o direito consuetudinário?}

Apesar das leis regionais de saúde pública do Pacífico serem largamente baseadas nas leis Britânicas do começo do Século XVIII, fortes influências internas da tradição ou "kastom" criaram arranjos legislativos e constitucionais únicos, os quais têm relevância na interpretação das leis de saúde pública. Vale destacar que alguns países da região agiram em prol da preservação de suas formas de organização social, com princípios, em geral, inseridos nas constituições.

Em Vanuatu, o Conselho Nacional de Chefes é reconhecido pela constituição, tem competência geral para discutir todos os assuntos relacionados com os costumes e tradições e pode fazer recomendações para a preservação e promoção da cultura e da língua ni-Vanuatu ${ }^{(46)}$. O Conselho pode ser consultado sobre qualquer questão, particularmente aquelas relativas às tradições, vinculada a qualquer projeto parlamentar ${ }^{(47)}$. Porém, conversas informais com os ni-Vanuatu sugerem que os poderes constitucionais do Conselho não são muito utilizados.

Na Emenda Constitucional de Fiji de 1997, o Bose Levu Vakaturaga (conhecido como o Grande Conselho de Chefes), estabelecido pelo Decreto de Negócios de Fiji, continua vigente e seus integrantes, funções e procedimentos são determinados de tempos em tempos pelo mesmo Decreto e suas funções conferidas pela Constituição. Além disso, o Parlamento deve garantir a aplicação do direito consuetudinário e resolver disputas de acordo com os processos tradicionais do país.

Dessa maneira, o Parlamento deve respeitar os costumes, tradições, usos, valores e aspirações da população local e do povo Rotuman ${ }^{(48)}$. Devese destacar que a constituição de Fiji foi revogada pelo Presidente Josepha Iloilo, em 10 de abril de $2009^{(49)(50)}$, e nenhum novo texto a substituiu.

(45) JOWITT, Foukona; Tom'Tavala. op. cit., p. 2.

(46) Constitution, Section 30(1).

(47) Constitution, Section 30(2).

(48) The Fiji Islands Constitution Amendment Act 1997, Section 186 (1) and (2)

(49) MARCOVIC, N. A timeline of the 2009 political crisis in Fiji and key regional reactions Foreign

Affairs, Defence and Security Section. Disponível em: <http://www.aph.gov.au/library/pubs/bn/fads/

Fiji.htm\#_Toc236559891>. Acesso em: 05 ago. 2010.

(50) Em abril de 2009, o "governo interino" das Ilhas Fiji revogou a constituição, dissolveu o Judiciário e começou a governar por decreto. Uma revisão constitucional será iniciada em setembro 
Nas Ilhas Salomão, um novo desenho de carta constitucional está em avaliação. $O$ texto inclui esforços consideráveis para utilizar tanto o direito consuetudinário como as proteções aos direitos humanos. Tratando de seu conteúdo e da sua predecessora, um pesquisador comentou que: "A vasta divisão entre o sistema legal e a governança de um lado e a autoridade e práticas tradicionais de outro foi finalmente alcançada."(51)

Enquanto a constituição é a lei suprema de Vanuatu(52), o direito consuetudinário faz parte do direito do país. Isto acontece em Papua Nova-Guiné e nas Ilhas Salomão.

Em Tonga, a constituição não menciona o direito consuetudinário, nem Ihe dá nenhum status em particular. O Decreto Governamental garante a qualquer oficial distrital a responsabilidade de atuar, para o governo ${ }^{(53)}$, como regulador dos assuntos da vila.

Na Papua Nova-Guiné, os Objetivos Nacionais e Princípios Diretivos mencionam especificamente a importância do "estilo do povo paupásia"(54), incluindo um chamado para que "as vilas tradicionais e comunidades permaneçam como unidades viáveis da sociedade de Papua Nova-Guiné e para que sejam tomadas medidas para a melhoria da qualidade cultural, social, econômica e ética". A constituição também afirma que as leis do país incluem as leis fundamentais ${ }^{(55)}$. A constituição permite ao Parlamento declarar as leis fundamentais da nação e propiciar seu desenvolvimento. Isto foi feito via o Decreto de Reconhecimento das Tradições, de 2000.

"Tradição" é definida pela constituição como "os costumes e usos dos habitantes indígenas do país em relação ao assunto em questão, no momento e local em que este assunto surja, independentemente se este costume ou uso tenha existido desde tempos imemoriais". Esta definição afirma claramente que tradição é o costume local em relação a uma determinada matéria, não importando se a tradição é relativamente nova ou velha ${ }^{(56)}$.

Nas palavras do chefe de Justiça de Vanuatu, Vincent Lunabeck:

Temos a constituição e a constituição é a lei básica, a lei fundamental, é claro. A constituição estabele um sistema de justiça a ser administrado pela tradição. A constituição estabelece também que os costumes devem ser parte das leis da república. Então, temos um sistema legal

de 2012, de acordo com as recomendações do Conselho Nacional para a Construção de uma Fiji Melhor, de 2008. V. Hassall, Op Cit, Page 13

51) CORRIN, Jennifer. op. cit., p. 144.

(52) Constitution, Section 2.

(53) Government Act (Tonga) Section 26, Village Regulations.

(54) Constitution of the Independent State of Papua New Guinea, National Goals and Directive Principles.

(55) Constitution of the Independent State of Papua New Guinea, Section 9.

(56) Constitution of the Independent State of Papua New Guinea, Schedule 1. 
dual, caso a lei escrita entre em conflito com a tradição. Antes que o conflito acredite que existe espaço, um grande espaço para os dois sistemas coexistirem (sic). Numa observação geral de Vanuatu, nota-se que um grande número de ilhas não conta com polícia, assim a questão é quem ou qual instituição mantém a paz e a ordem no lugar da polícia? Os chefes - a resposta é os chefes. ${ }^{(57)}$

Em vilas de Papua Nova-Guiné, os habitantes dizem "sabemos da constituição, mas nós a colocamos embaixo da mesa e usamos nosso estilo tradicional"(58).

A inserção do direito consuetudinário nas constituições das Ilhas do Pacífico mostra o desejo dos parlamentares destes países de promover este direito assim como os direitos humanos ${ }^{(59)}$.

A lei modelo de saúde pública para o Pacífico ainda está sendo finalizada, porém, este trabalho inclui algumas ideias em forma de diagrama, mostrando como é possível ilustrar as oportunidades de incorporação das abordagens tradicionais e de direitos humanos em único modelo de lei.

(57) Comentário feito no programa radiofônico "TIME TO TALK" program on Justice, Law and Order in the Pacific broadcast on Radio Australia 2008. Disponível em: <http://www.radioaustralia.net.au/ pdf/timetotalk/timetotalk_9.pdf>. Acesso em: 14 Maio 2009.

(58)Village Courts Secretariat PNG, unpublished report on Custom, Women and Village Courts Project, 2009.

(59) CORRIN, Jennifer. op. cit., p. 144. 
FIGURA 1 - Oportunidades de aplicação dos direitos humanos ${ }^{(60)}$

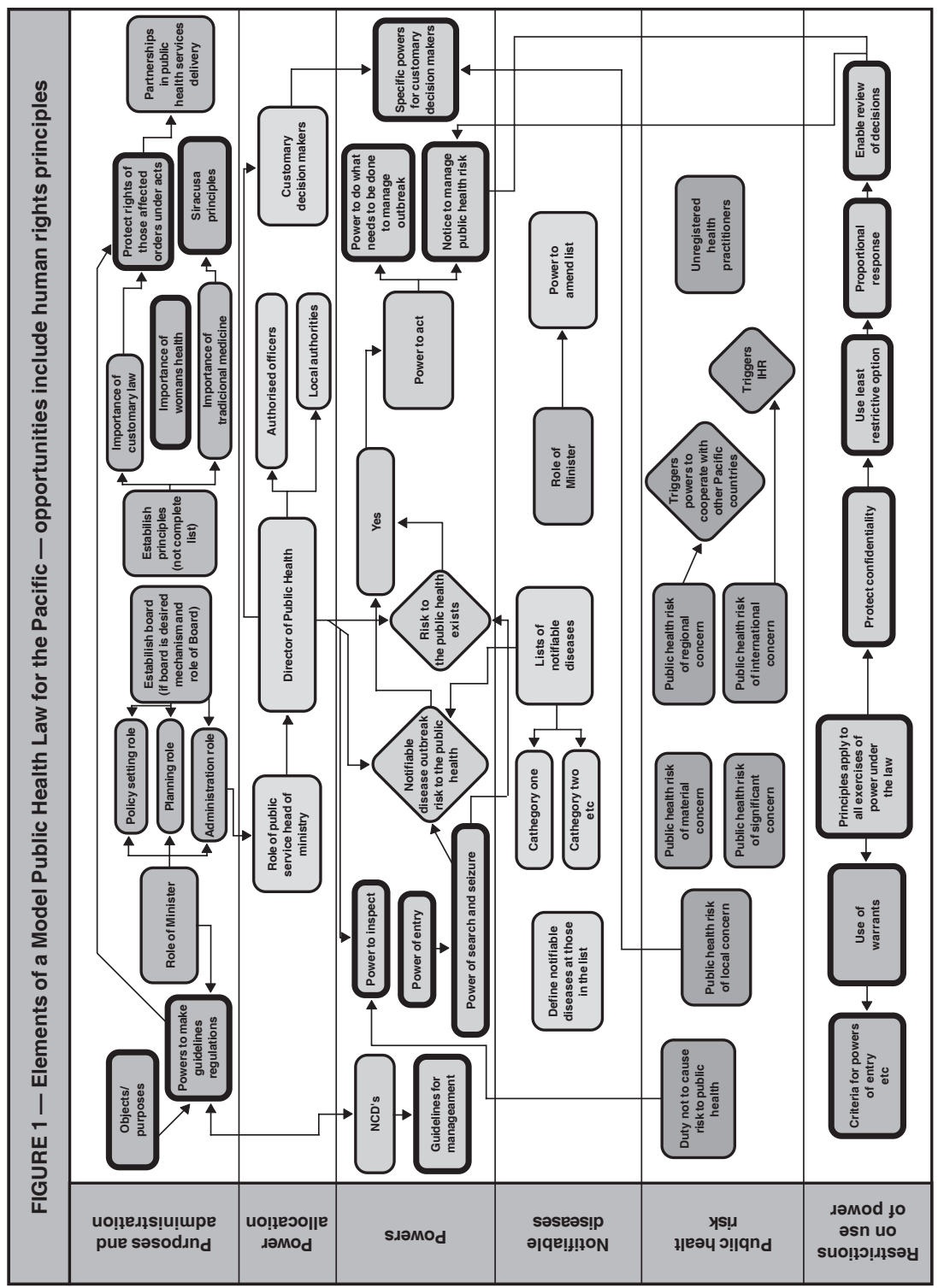

(60) Nota do editor: manteve-se a versão original da figura em Inglês 
Nota-se que as oportunidades são identificadas em três de cinco módulos: Purposes and Administration (Objetivos e Gestão); Powers (Poderes) e Restrictions on use of powers (Restrições ao uso dos poderes).

Não pretendemos oferecer uma descrição extensa dos módulos que compõem este modelo de lei. Os itens a seguir abordam as oportunidades identificadas para a implementação e aplicação das obrigações de direitos humanos dentro deste modelo.

\section{OBJETIVOS E GESTÃO - PRINCÍPIOS}

Algumas leis de saúde pública atuais estabelecem princípios pelos quais a legislação deve ser operacionalizada, interpretada e administrada(61), princípios que também podem fazer parte do papel que a lei terá para a realização das diversas obrigações dos tratados internacionais ${ }^{(62)}$.

\section{O princípio do acesso da mulher aos cuidados de saúde}

Alguns modelos de cuidados de saúde não se mostram acessíveis às mulheres e devem ser melhorados. A inclusão do princípio de acesso das mulheres aos cuidados de saúde é consistente com as obrigações assumi-das no Comitê para a Eliminação de todas as Formas de Discriminação contra a Mulher, sendo que os arts. 12 e $14^{(63)}$ estão relacionados diretamente com a saúde.

\section{Princípios específicos}

São princípios que orientam as disposições para limitar a liberdade das pessoas para a proteção da saúde pública:

(61) South Australian Public Health Bill, Op Cit

(62) Todos os países do Pacífico são integrantes da Organização Mundial de Saúde o que os obriga a implementar o Regulamento Internacional de Saúde.

(63)Artigo 12 relaciona a eliminação da discriminação contra as mulheres no campo dos cuidados com a saúde, garantindo acesso aos serviços de saúde, inclusive os relacionados ao planejamento familiar, pós-natal, garantia de serviços gratuitos quando necessário, assim como nutrição adequada durante a gravidez e a amamentação. Artigo 14 faz referência em particular aos direitos das mulheres que vivem em zonas rurais. V. CONVENTION on the Elimination of All forms of Discrimination Against Women. Disponível em: <http://www.un.org/womenwatch/daw/cedaw/text/econvention.htm\#>. Acesso em: 19 nov. 2010. 
- uma pessoa que tenha sua liberdade limitada deve ter sua privacidade respeitada e o benefício do sigilo;

- deve receber os cuidados e tratamentos necessários e ter sua dignidade respeitada, sem nenhuma discriminação além da razoavelmente necessária para a proteção da saúde pública;

- na medida em que for possível e apropriado, permitir que a pessoa participe do processo decisório relacionado a sua condição individual e informá-la das razões para as decisões tomadas e

- ser submetida a restrições (se necessário) proporcionais aos riscos apresentados à sociedade (considerando a natureza da doença ou da condição médica, o estado de saúde da pessoa e seu comportamento, entre outros fatores relevantes).

\section{Princípio da parceria}

Organizações em parceria com o governo para a prestação de serviços de saúde devem implementar programas em cumprimento à Declaração de Paris sobre a Eficácia da Ajuda ao Desenvolvimento.

\section{PODER PARA A ELABORAÇÃO DE GUIAS E REGULAMENTOS}

A lei modelo prevê competência para a elaboração de diretrizes para a execução de seus princípios. Trata-se de uma oportunidade para o governo detalhar alguns princípios em prol da proteção dos direitos humanos. Diretrizes não são vinculantes, mas podem ser um mecanismo útil para mostrar, àqueles que são afetados pela lei, como o governo pretende implementar os princípios. O Poder Judiciário também deve considerá-las na interpretação de sua amplitude e conteúdo.

A seguir, algumas sugestões para a elaboração das diretrizes de prestação de serviços de saúde, considerando a importância do cumprimento da Declaração de Paris sobre a Eficácia da Ajuda ao Desenvolvimento.

\section{Sugestão de diretrizes para as parcerias para prestação de serviços}

Organizações religiosas e não governamentais têm um longo histórico de prestação de serviços de saúde no Pacífico. Indústrias extrativas, 
mineradoras, empreendimentos agrícolas, entre outras, recentemente começaram a prestar este tipo de serviço, principalmente em Papua Nova-Guiné. A qualidade e o número de arranjos público-privados vêm crescendo consideravelmente e ministros da saúde reconhecem a necessidade de se ter uma política apropriada com relação a parcerias com instituições não governamentais.

Há uma série de benefícios na entrada destas instituições no campo da saúde. Em geral, os governos encorajam esta participação, o que deve ser feito dentro de uma estrutura política coerente, que reconheça que:

- o ministério da Saúde tem uma política e um planejamento para a área;

- todos os acordos de parceria devem reconhecer esta política e planejamento e devem seguir as direções governamentais;

- todos os acordos devem ser consistentes com o Plano Nacional de Saúde;

- qualquer proposta para uma parceria público-privada deve considerar as responsabilidades legais das agências governamentais e dos planos de saúde e deve se adequar a estes serviços, evitando a duplicação de serviços, o desperdício de recursos e a "desqualificação" dos agentes do governo;

- é papel do ministro da Saúde garantir a equidade de acesso e de qualidade dos serviços prestados no país, princípios que devem ser levados em consideração nas decisões sobre como e onde serão estabelecidas as parcerias;

- a saúde individual de mulheres e crianças deve ser considerada em qualquer acordo de parceria público-privada;

- qualquer parceria deve trabalhar ou reforçar o sistema de saúde existente, tal como estabelecido pela legislação e políticas vigentes. O sistema não pode ser enfraquecido ou minado.

\section{Poderes}

É importante que os gestores do ministério da Saúde tenham amplos poderes, que os permitam tomar medidas de controle de surtos de doenças transmissíveis e de riscos à saúde pública; tais poderes são característicos da legislação em saúde. Mas restrições ao exercício de tais direitos são importantes para proteger os direitos humanos daqueles que estão sujeitos $\mathrm{a}$ ordens e às medidas tomadas ao abrigo dos poderes. 


\subsection{Poderes para inspeção, busca e apreensão}

Limites devem ser colocados no exercício dos poderes de invasão de domicílio, inspeção, busca e apreensão de maneira a proteger os direitos humanos. Os limites incluem a necessidade de se justificar a inspeção, que deve ocorrer em horário razoável. Além disso, aqueles afetados pela ação devem ser informados da natureza da inspeção e de seus direitos, incluindo o direito de recorrer da decisão.

\subsection{Poder para agir em caso de surto de doenças transmissíveis}

Os princípios gerais já mencionados se aplicam a esta situação.

\subsection{Poder de ação em caso de riscos à saúde pública}

Deve-se impor limites no exercício desse poder de maneira a proteger os direitos humanos. Os limites incluem a justificativa para a ação, a proporcionalidade e a escolha da opção menos restritiva. Além disso, aqueles afetados pela ação devem ser informados da natureza da inspeção e de seus direitos, incluindo o direito de recorrer da decisão. 
FIGURA 2 - Áreas na lei modelo de saúde pública consideradas oportunidades para a aplicação de abordagens tradicionais para a promoção e proteção da saúde ${ }^{(64)}$.

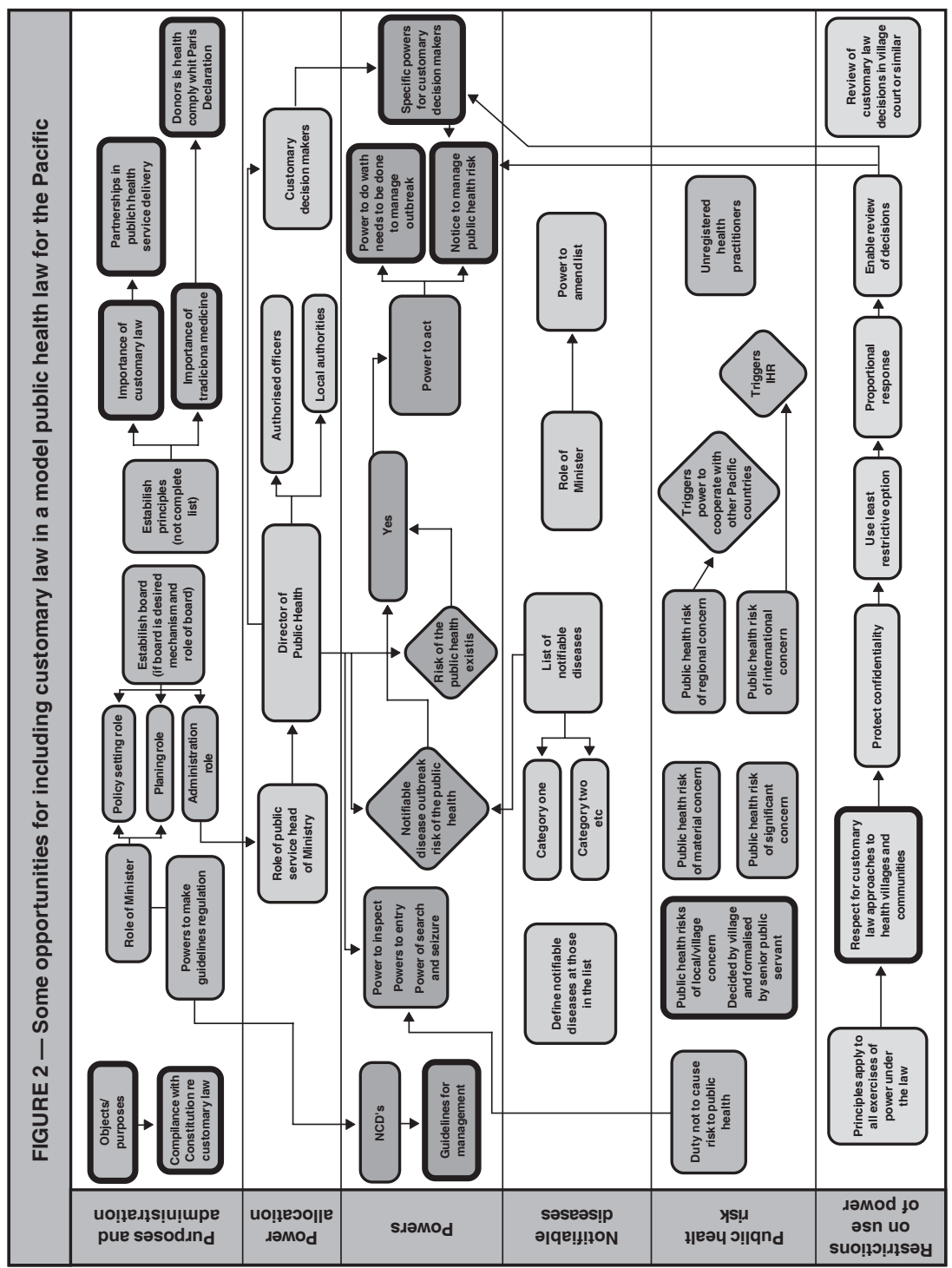

(64) Nota do editor: manteve-se a versão original da figura em Inglês 
Nota-se que as oportunidades são identificadas em quatro de cinco módulos: Purposes and Administration (Objetivos e Gestão); Powers (Poderes); Public Health Risk (Riscos à Saúde Pública) e Restrictions on use of powers (Restrições ao uso dos poderes).

\section{OBJETIVOS E GESTÃO}

\section{Cumprimento da constituição e do direito consuetudinário}

Um dos objetivos da lei é o de cumprir os requisitos constitucionais de aplicação do direito consuetudinário, no contexto da saúde.

\subsection{Princípio da importância da abordagem tradicional e a lei na saúde da população}

Este princípio foi elaborado para exigir que se considere a abordagem do direito consuetudinário na interpretação da lei, naturalmente consistente com as determinações constitucionais.

\subsection{Princípio da importância da medicina tradicional}

O reconhecimento da medicina tradicional é importante em uma região onde as pessoas vivem predominantemente em áreas rurais, quase sem acesso à assistência básica em saúde. Algumas vezes, a medicina tradicional é a única opção.

\subsection{Princípios aplicados às parcerias na prestação de serviços de saúde}

Tratamos destes princípios anteriormente. No entanto, em acréscimo aos pontos mencionados, tais parcerias devem incluir associações com as comunidades, as quais devem ser reconhecidas e amparadas pela lei modelo.

\section{Poderes}

\subsection{Poderes para os líderes tradicionais}

Como parte dos estudos elaborados para a criação de uma lei modelo de saúde pública, o artigo "Lei modelo de saúde pública para o Pacífico - 
Direito consuetudinário e saúde pública", elaborado por pesquisadores da Universidade do Sul do Pacífico, em 2009, examinou a interface entre o direito consuetudinário e a legislação em saúde pública, utilizando estudos de casos em três países, Vanuatu, Papua Nova-Guiné e Ilhas Salomão.

O estudo levanta uma série de exemplos úteis, encontrados nas legislações dos países, de áreas nas quais o poder público e o poder tradicional interagem em um nível formal, como no Decreto de Gerenciamento da Água, de 2002 ${ }^{(65)}$ (Vanuatu); Decreto dos Comitês de Saúde, capítulo 296 (Vanuatu); Decreto da Pesca, de 1988 (Ilhas Salomão); Decreto da Administração Governamental em Nível Local, de 1997 (Papua Nova Guiné) e do projeto Tradição e Mulheres nas Cortes das Vilas, de 2010 (Papua Nova-Guiné)(66).

\section{ABORDAGENS SUGERIDAS}

Com base nas tradições locais, elaborar pronunciamentos sobre os problemas de saúde que afetam a vila, a partir de consultas com os agentes de saúde e de acordo com a legislação local. Estes pronunciamentos podem ser feitos em conjunto pelo representante do poder governamental local e o governador e após consulta com a população afetada.

Leis locais podem ter regras específicas sobre higiene, uso e locação de equipamentos sanitários, água potável etc. Estas leis também podem efetivar a divulgação de pronunciamentos sobre a importância da comunidade como um local de encontro, compartilhamento de alimentos, cuidados mútuos, respeito etc.

As leis locais também podem ser feitas em conjunto com os pronunciamentos baseados nas tradições, ou não. Quando um destes pronunciamentos é feito, pode ser reforçado nos tribunais da comunidade.

\section{CONSIDERAÇÕES FINAIS}

Uma lei modelo de saúde pública para o Pacífico é uma tarefa de risco. Desenvolvida em módulos, abordando questões políticas e com a inclusão de recomendações sobre as pré-condições para sua implementação, a lei modelo é um ponto de partida para os países que se esforçam para obter

(65) V. PHILIP, Hirsch, 'Case Study of Vanuatu', South East Asia Geography Conference Panel: Water Governance in Context. Disponível em: <http://www.mekong.es.usyd.edu.au/events/past/ GeogConference2004/vanuatu_casestudy.pdf>. Acesso em: 05 set. 2009.

(66) VILLAGE Courts Secretariat, Custom, Women and Village Courts, Pilot Project Manus Island, Phases One and Two, Unpublished report, 2009. 
recursos para reformar leis ultrapassadas e fora de sintonia com as políticas correntes dos governos do Pacífico de promoção da saúde e prevenção de doenças.

Em um ambiente legal pluralista, reformas nas leis de saúde pública devem considerar os arranjos confusos de leis e de obrigações legais, advindas de tratados internacionais, o direito internacional consuetudinário, as leis locais "transplantadas" do Ocidente e a rica e variada tradição do direito consuetudinário e modelos de organização social. As leis que repercutem sobre as pessoas afetadas por elas são as mais importantes a serem trabalhadas. É difícil criar mecanismos que tentam remodelar princípios internacionais para torná-los mais acessíveis aos habitantes de vilas e comunidades. Isso cria uma pletora de acordos que podem parecer estranhos para um observador internacional, mas que são mais familiares e praticáveis para as comunidades tradicionais do que uma longa convenção de artigos em uma língua estrangeira. Os elaboradores de leis devem desafiar ortodoxias e estar dispostos a ver princípios puros alterados. O trabalho é encontrar um caminho, a partir dos escritórios de Nova lorque e Genebra, que seja útil nas remotas aldeias das ilhas do Pacífico.

\section{REFERÊNCIAS BIBLIOGRÁFICAS}

AusAID, FAQ on Paris Declaration on Aid Effectiveness. Disponível em: <http:/ /www.ausaid.gov.au/ode/pdf/faq_paris.pdf>. Acesso em: 19 nov. 2010.

AUSTRALIAN Human Rights Commission. Human Rights Explained. Disponível em: <http://www.humanrights.gov.au/education/hr_explained/ index.html>. Acesso em: 19 nov. 2010.

AUSTRALIAN HUMAN RIGTS COMMISSION. Disponível em: <http:// www.hreoc.gov.au/education/hr_explained/5_international.html>. Acesso em: 27 out. 2010.

COMMITTEE on Economic, Social and Cultural Rights. Global Governance watch. Disponível em: <http://www.globalgovernancewatch.org/resources/ general-comment-no-14-the-right-to-the-highest-attainable-standard-ofhealth>. Acesso em: 03 nov. 2010.

CONSTITUTION Amendment Act 1997 (Fiji Islands).

CONSTITUTION of the Independent State of Papua New Guinea.

CONSTITUTION of the Republic of Vanuatu 1978.

CONSTITUTIONAL Planning Committee, Constitutional Planning Committee Report, 1974. Disponível em: <http://www.paclii.org/pg/CPCReport/Cap2.htm>. Acesso em: 19 jan. 2009. 
CONVENTION on the Elimination of All forms of Discrimination Against Women. Disponível em: <http://www.un.org/womenwatch/daw/cedaw/text/ econvention.htm\#>. Acesso em: 19 nov. 2010.

COOK Islands, Federated States of Micronesia, Fiji, Kiribati, Nauru, Niue, Palau, Papua New Guinea, Republic of Marshall Islands, Samoa, Solomon Islands, Tonga, Tuvalu, Vanuatu. Disponível em: <http://www.forumsec.org.fj/ pages.cfm/about-us/member-countries>. Acesso em: 16 nov. 2010.

CORRIN, Jennifer. Breaking the Mould: Constitutional Review in the Solomon Islands. Revue Juridique Polynesienne, n. 13, 2007.

FORSYTH, Miranda. A Bird that Flies with Two Wings - Kastom and State Justice Systems in Vanuatu, ANU E Press, 2009.

Government Act (Tonga)

HASSALL, G. Constancy and Change; A Perspective on Constitutional Reform "the Pacific Way", Conference Paper at Fourteenth Annual Public Law Weekend, Centre for International and Public Law, Australian National University, Canberra, 12-13 November 2009.

HOWSE, G. A Model Public Health Law for the Pacific, Programme Methods. Public Health, v. 123, n. 3, Mar. 2009.

IESCR Article 2(1). See See WHO, Health and Human Rights, the International Covenant on Economic, Social and Cultural Rights. Disponível em: <http:// www.who.int/hhr/Economic_social_cultural.pdf>. Acesso em: 02 nov. 2010.

ILHAS Cook, Estados Federados da Micronésia, Fiji, Kiribati, Nauru, Niuê, Papua Nova-Guiné, República das Ilhas Marshall, Samoa, Ilhas Salomão, Tonga, Tuvalu, Vanuatu. Disponível em: <http://www.forumsec.org.fj/ pages.cfm/about-us/member-countries/>. Acesso em: 15 nov. 2010.

JOWITT, Anita. The Future of Law in the South Pacific. Journal of South Pacific Law, v. 12, n. 1, 2008. Disponível em: <http://www.paclii.org/journals/fJSPL/ vol12no1/pdf/jowitt.pdf>. Acesso em: 19 Nov. 2010.

JOWITT, Foukona; Tom'Tavala. Model Public Health Law for the Pacific Project - Customary Law and Public Health, Unpublished Paper by Scholars from the University of the South Pacific for the Model Public Health Law for the Pacific Project. At the time of writing, there were plans to submit the paper for publication along with a series of papers on the project. Journal of South Pacific Law, 2011.

KIRBY, J. The First Ten Years of the Bangalore Principles on the Domestic Application of International Laws. Disponível em: <http://www.hcourt.gov.au/ speeches/kirbyj/kirbyj_bang11.htm>. Acesso em: 04 fev. 2009.

Local-level Government Administration Act (PNG) 
MARCOVIC, N. A timeline of the 2009 political crisis in Fiji and key regional reactions Foreign Affairs, Defence and Security Section. Disponível em: <http:/ /www.aph.gov.au/library/pubs/bn/fads/Fiji.htm\#_Toc236559891>. Acesso em: 05 ago. 2010.

MATHESON, Howse et al, Papua New Guinea, Health Partnerships - Final Report, WHO 2009. Disponível em: <http://www.wpro.who.int/NR/rdonlyres/C58D94C00117-43C7-8359-963DFAFA90B8/0/PNGHealthPartnershipsFinalReport.pdf> Acesso em: 20 nov. 2010.

MEDIUM Term Development Strategy 2005 to 2010 PNG. Disponível em: <http://www.aciar.gov.au/publication/EXT02>. Acesso em: 19 nov. 2010.

MERRY, Sally Engle quoted. In: GOODALE; MERRY (Eds). The Practice of Human Rights - Tracking Law Between the Global and the Local, Cambridge University Press, 2007.

MERRY, Sally Engle. Legal Transplants and Cultural translation: Making Human Rights in the Vernacular. In: Human Rights and Gender Violence - Translating International Law into Local Justice, University of Chicago Press, 2006.

OFFICE of the UN High Commissioner for Human Rights, An introduction to the core human rights treaties and the treaty bodies, Fact Sheet No 30. Disponível em: <http://www.ohchr.org/Documents/Publications/ FactSheet30en.pdf>. Acesso em: 27 out. 2010.

PACIFIC Islands Legal Information Institute. Disponível em: <www.paclii.org>. Acesso em: 16 nov. 2010.

PARIS Declaration on Aid Effectiveness and the ACCRA Agenda for Action. Disponível em: <http://www.oecd.org/dataoecd/11/41/34428351.pdf>. Acesso em: 26 out. 2010. with list of participating countries and organisations at Appendix B.

PHILIP, Hirsch, 'Case Study of Vanuatu', South East Asia Geography Conference Panel: Water Governance in Context. Disponível em: <http:// www.mekong.es.usyd.edu.au/events/past/GeogConference2004/ vanuatu_casestudy.pdf>. Acesso em: 05 set. 2009.

Shiyan SUN. The Understanding and Interpretation of the ICCPR in the context of China's Possible Ratification. Chinese Journal of International Law, v. 9, n. 3, p. 17-42, Sept. 2010.

SOUTH AUSTRALIAN Public Health Bill. Disponível em: <http:// www.health.sa.gov.au/pehs/PublicHealthBill-09/publichealthbilldraft-pehsahealth-2009.pdf>. At the time of writing the Bill was before the South Australian Parliament.

THE NATIONAL, PNG, editorial "Still the Weaker Sex", 10 Oct. 2008. 
"TIME TO TALK" program on Justice, Law and Order in the Pacific broadcast on Radio Australia 2008, see. Disponível em: <http://www.radioaustralia.net.au/ pdf/timetotalk/timetotalk_9.pdf>. Acesso em: 14 Maio 2009.

TRINDADE, Antônio Augusto Cançado. Introduction to the Universal Declaration of Human Rights. Disponível em: <http://untreaty.un.org/cod/avl/ ha/udhr/udhr.html>. Acesso em: 17 nov. 2010.

TURNER and May, Policy making in Papua new Guinea, a conference paper present ted to a Workshop run by the State Society in Melanesia project, Feb. 2002. Disponível em: <http://rspas.anu.edu.au/papers/melanesia/ conference_papers/2002/PNGPolicyMakingMAYTURNEROverviewRTF.rtf>. Acesso em: 13 out. 2008.

UN, United Nations Treaty Reference Guide. Disponível em: <http:// untreaty.un.org/English/guide.asp>. Acesso em: 18 nov. 2008.

UNITED NATIONS, UNDHR, Questions and Answers. Dispoível em: <http:// www.udhr.org/history/question.htm\#_Toc397930429>. Acesso em: 18 out. 2010.

VILLAGE Courts Secretariat, Custom, Women and Village Courts, Pilot Project Manus Island, Phases One and Two, Unpublished report, 2009.

WASTELL, Sari, Being Swazi, Being Human: Custom, Constitutionalism and Human Rights in an African Polity. In: GOODALE; MERRY (Eds). The Practice of Human Rights; Tracking Law between the Global and the Local, Cambridge University Press, 2007.

WHO Press Release, Broad Support needed to fight rising non communicable diseases, Sixtieth Session of the Regional Committee for the Western Pacific, 21-25 September 2009, Hong Kong (China)

WHO. Health and human rights, the international covenant on economic, social and cultural rights. Disponível em: <http://www.who.int/hhr/ Economic_social_cultural.pdf>. Acesso em: 02 nov. 2010.

WHO. Meeting on the Situation of Maternal Health and Newborn Health in the Pacific, Apr. 2009. Disponível em: <http://www.wpro.who.int/internet/ resources.ashx/RPH/Nadi+meeting+report+nov09.pdf>. Acesso em: 19 nov. 2010. 
THE NATIONAL, PNG, editorial "Still the Weaker Sex", 10 Oct. 2008.

"TIME TO TALK" program on Justice, Law and Order in the Pacific broadcast on Radio Australia 2008, see. Disponível em: <http://www.radioaustralia.net.au/ pdf/timetotalk/timetotalk_9.pdf>. Acesso em: 14 Maio 2009.

TRINDADE, Antônio Augusto Cançado. Introduction to the Universal Declaration of Human Rights. Disponível em: <http://untreaty.un.org/cod/avl/ ha/udhr/udhr.html>. Acesso em: 17 nov. 2010.

TURNER and May, Policy making in Papua new Guinea, a conference paper present ted to a Workshop run by the State Society in Melanesia project, Feb. 2002. Disponível em: <http://rspas.anu.edu.au/papers/melanesia/ conference_papers/2002/PNGPolicyMakingMAYTURNEROverviewRTF.rtf>. Acesso em: 13 out. 2008.

UN, United Nations Treaty Reference Guide. Disponível em: <http:// untreaty.un.org/English/guide.asp>. Acesso em: 18 nov. 2008.

UNITED NATIONS, UNDHR, Questions and Answers. Dispoível em: <http:// www.udhr.org/history/question.htm\#_Toc397930429 >. Acesso em: 18 out. 2010.

VILLAGE Courts Secretariat, Custom, Women and Village Courts, Pilot Project Manus Island, Phases One and Two, Unpublished report, 2009.

WASTELL, Sari, Being Swazi, Being Human: Custom, Constitutionalism and Human Rights in an African Polity. In: GOODALE; MERRY (Eds). The Practice of Human Rights; Tracking Law between the Global and the Local, Cambridge University Press, 2007.

WHO Press Release, Broad Support needed to fight rising non communicable diseases, Sixtieth Session of the Regional Committee for the Western Pacific, 21-25 September 2009, Hong Kong (China)

$\mathrm{WHO}$. Health and human rights, the international covenant on economic, social and cultural rights. Disponível em: <http://www.who.int/hhr/ Economic_social_cultural.pdf>. Acesso em: 02 nov. 2010.

WHO. Meeting on the Situation of Maternal Health and Newborn Health in the Pacific, Apr. 2009. Disponível em: <http://www.wpro.who.int/internet/ resources.ashx/RPH/Nadi+meeting+report+nov09.pdf>. Acesso em: 19 nov. 2010. 